BMJ Nutrition,

Prevention \& Health

\section{Food insecurity and men's perpetration of partner violence in a longitudinal cohort in South Africa}

To cite: Hatcher AM, Neilands TB, Rebombo D, et al. Food insecurity and men's perpetration of partner violence in a longitudinal cohort in South Africa. BMJ Nutrition, Prevention \& Health 2022;0:e000288. doi:10.1136/ bmjnph-2021-000288

${ }^{1}$ Department of Health Behavior, Gillings School of Global Public Health, University of North Carolina System, Chapel Hill, North Carolina, USA

${ }^{2}$ School of Public Health, Faculty of Health Sciences, University of the Witwatersrand, Johannesburg, South Africa ${ }^{3}$ Department of Medicine, University of California San Francisco, San Francisco, California, USA

${ }^{4}$ Sonke Gender Justice, Johannesburg, South Africa ${ }^{5}$ School of Public Health, University of the Witwatersrand Faculty of Health Sciences, Johannesburg, Gauteng, South Africa

Correspondence to Dr Abigail M Hatcher, University of North Carolina System, Chapel Hill, NC 27514, USA; abbeyhatcher@gmail.com

Received 5 August 2021 Accepted 17 January 2022

Check for updates

(C) Author(s) (or their employer(s)) 2022. Re-use permitted under CC BY. Published by BMJ.

\section{ABSTRACT}

Background Although food insecurity has been associated with intimate partner violence (IPV), few studies examine it longitudinally or among male perpetrators. Methods We used secondary data from a trial that followed 2479 men in a peri-urban settlement in South Africa (February 2016-August 2018). Men self-completed questionnaires at baseline (T0), 12 months (T1) and 24 months (T2) on food security, household type, relationship status, childhood abuse exposure, alcohol use, and perpetration of physical and/or sexual IPV. Cross-lagged dynamic panel modelling examines the strength and direction of associations over time.

Results At baseline, rates of IPV perpetration (52.0\%) and food insecurity $(65.5 \%)$ were high. Food insecure men had significantly higher odds of IPV perpetration at T0, T1 and T2 (ORs of 1.9, 1.4 and 1.4, respectively). In longitudinal models, food insecurity predicted men's IPV perpetration 1 year later. The model had excellent fit after controlling for housing, relationship status, age, childhood abuse and potential effect of IPV on later food insecurity (standardised coefficient $=0.09, p=0.031$. root mean squared error of approximation $=0.016$, comparative fit index=0.994). IPV perpetration did not predict later food security $(p=0.276)$. Conclusion Food insecurity had an independent, longitudinal association with men's IPV perpetration in a peri-urban South African settlement. These findings suggest food security could be a modifiable risk factor of partner violence.

Trial registration number NCT02823288.

\section{INTRODUCTION}

Intimate partner violence (IPV) is a major burden to human rights and health across the globe, with one-quarter of women reporting IPV exposure in their lifetime. Despite considerable research to understand the predictors of women's IPV exposure, less is known about the factors associated with men's IPV perpetration.

Poverty may be a strong underlying driver of men's IPV perpetration. North American cross-sectional research shows that men who are unemployed have higher rates of perpetrating IPV, ${ }^{23}$ as do men with lower income. Cross-sectional research from India finds that

\section{What this paper adds}

This paper is the first to examine food insecurity and intimate partner violence (IPV) perpetration longitudinally.

- Among 2384 men living in a peri-urban South African settlement, rates of past-year food insecurity $(65.5 \%)$ and IPV perpetration $(52.0 \%)$ and were high.

-We found a small but significant effect of men's selfreported food insecurity on their use of violence a year later.

men with fewer household assets have greater odds of perpetrating IPV. ${ }^{56}$ An eight-country study across sub-Saharan Africa identified no relationship between poverty and IPV perpetration. ${ }^{7}$ In rural South Africa, men who were better off (in contexts of high poverty) were more likely to enact violence against a partner. ${ }^{8}$

This complex cross-sectional relationship is only starting to be parsed out in longitudinal research. A recent systematic review identified fewer than a dozen longitudinal studies on IPV perpetration, and all were conducted in high-resource settings. ${ }^{9}$ Two longitudinal studies of poverty and men's IPV perpetration offer mixed evidence. Krishnan and colleagues learnt in India that men whose employment opportunities worsened had higher odds of perpetrate IPV. ${ }^{10}$ Fox and colleagues found in the USA, however, that while employment status had no association with later IPV, financial well-being at baseline was strongly associated with IPV perpetration 6 years later. ${ }^{11}$

Preliminary evidence suggests a relationship between food insecurity - a sensitive marker of poverty-and IPV. When measured using a validated scale, food security scales provide a 'snapshot' of a household situation with regards to meeting basic needs. ${ }^{12}$ Food insecurity is associated with increased odds of IPV exposure among women ${ }^{13-15}$ 
and increased odds of men's perpetration of IPV. ${ }^{16} 17$ In a systematic review of the literature, all extant literature on men's perpetration of IPV and food insecurity is cross-sectional, ${ }^{18}$ highlighting the need for longitudinal research on these intersecting conditions.

One conceptual challenge to assessing cross-sectional research on poverty and IPV perpetration is that violence and poverty may have a bidirectional relationship. Evidence among women survivors shown that IPV has a negative effect on economic earning potential years after the violence occurs. ${ }^{19}$ Less is known about IPV leading to poverty among male perpetrators, but there are several plausible explanations for a link. IPV perpetration may lead to greater household poverty if it increases financial burden for the family. This is consistent with research that demonstrates a high cost associated with the injuries, mental debilitation and loss of work for IPV survivors. ${ }^{20}$ Alternately, IPV perpetration could make relationships more unstable, leading to a decreased ability of the household to secure food. Finally, IPV perpetration is strongly associated with unplanned pregnancy, ${ }^{21}$ a life event that could worsen household poverty as resources are extended. ${ }^{22}$

\section{METHODS}

The current study aims to determine the direction and strength of the longitudinal association between food insecurity and men's perpetration of IPV. Secondary data from a cluster randomised control trial were collected from men at three-time points in a peri-urban setting in South Africa.

\section{Data collection}

Trained research assistants recruited a volunteer sample of men from a peri-urban settlement (also called a former 'township') near Johannesburg. The settlement has high levels of poverty and residents perceive safety to be very low. ${ }^{23}$ While some houses are brick, electrified and have running water, many are shacks constructed with sheet metal who use community taps and toilets.

The research was conducted during the period of February 2016-August 2018. Eligible men lived in a predefined research area (called a cluster) for at least 12 months and were aged $18-40$ years. The sample was recruited by a local mobilisation team who used convenience sampling methods during daytime hours at local places (schools, street corners, outside restaurants) within a total of 18 clusters for a cluster randomised controlled trial.

After taking part in the baseline (T0) questionnaire, a community even was held to randomly allocated clusters to an intervention arm or a control arm of the trial. The intervention has been detailed elsewhere, ${ }^{24}$ but briefly it involved community mobilisation around the issue of IPV through group meetings, door-to-door communication campaigns and engaging local leaders. Men participating in the trial lived in areas of intervention or control work, but may not have directly participated. These men were followed up approximately 12 months after baseline (T1) and again at 24 months after baseline (T2).

Research assistants asked participants at baseline (T0) to complete a locator form with contact names and numbers of the participant and close friends or family. Participants were contacted via phone call and text message at $\mathrm{T} 1$ and T2 and invited to complete the questionnaire at a convenient place in their neighbourhood. Efforts to trace men consisted of: multiple calls to cell phones, contacting next of kin, friends and other participants who had listed them as friends, home visits to addresses where men reported living, walks around the cluster to ask neighbours, and home visits to other provinces, cities and neighbourhoods within Johannesburg.

Data collection was conducted in the language of participant choice (English, isiZulu, Tswana or Sepedi) on tablet computers using audio-computer assisted data collection (ACASI) software. ACASI allows important data to be collected about socially desirable and undesirable (including illegal) activity while ensuring anonymity. Data from tablets were uploaded multiple times daily to an encrypted server housed at the University of the Witwatersrand.

Participation was on the basis of written, informed consent and each participant was reimbursed R50 (approximately US\$3.50) at T0, R100 (US\$7) at T1 and R150 (US $\$ 10.50$ ) at T2. These participant reimbursement rates were somewhat lower than those used by South African clinical trials because participants did not need to travel far-each study visit was walkable within about $10 \mathrm{~min}$ by foot. We anticipate this lower rate helped reduce the economic incentives of participation, though in a setting where work is scarce it is plausible that some men took part due to this reimbursement.

Researchers received intensive training on IPV, the study protocol, collecting sensitive information, and ensuring data quality and participant confidentiality. Study procedures complied with ethical recommendations of the United Nations Multi-Country Study on Men and Violence.

Community members were involved before quantitative research started, through a series of in-depth interviews with men living within the area, meetings with civil society organisations, and a community advisory board. These formative steps informed the development of research questions and the design of the trial questionnaire. Local interviewers were hired to conduct the research and lead recruitment of community members into the study. We held three community workshops: prior to trial start a new study with men about relationships was introduced without using the term 'violence'; on baseline data collection completion we randomly selected which neighbourhoods would be in intervention or control arms of the trial; after the trial was analysed we shared information about the null primary findings (ie, the intervention had no effect on men's IPV perpetration). 


\section{Measures}

Dependent variable

IPV perpetration was measured as an index of items on physical and sexual violence towards a current or ex-partner in the past year using the WHO Multi-Country Study Instrument $^{25}$ (a full version of which can be found here ${ }^{26}$ ). A total of 17 items asked about behaviourally specific acts (eg, hitting, choking, forcing sex) with answers on a Likert-type scale scored as 0 (never), 1 (once), 2 (two to three times), 3 (four or more times). IPV was defined in two ways. In logistic regression it was defined dichotomously. A person who reported using one or more forms of psychological, physical and/or sexual violence was considered as having past-year IPV perpetration. In the dynamic panel modelling IPV was treated as a continuous measure of intensity (summing the responses with a range of 0-39). Internal consistency of the IPV instrument was strong (Cronbach's $\alpha=0.93,0.93,0.94$ at baseline, midline and endline, respectively). In supplemental analysis IPV was defined as a dichotomous measure (any IPV perpetration vs none).

\section{Time-variant explanatory variables}

Food insecurity is defined as having uncertain or limited availability of nutritionally adequate food or the inability to acquire safe, acceptable foods. ${ }^{27}$ Beyond sheer hunger from insufficient food intake, food insecurity also includes poor dietary quality and worry or anxiety over securing food supplies. ${ }^{28}$ Food insecurity was measured using three items of the Household Food Insecurity Access Scale that have been validated as a measure of household hunger ${ }^{29}$ : (1) having no food in the house, (2) going to sleep hungry and (3) going without food. ${ }^{29}$ In addition, two items important to this highly impoverished setting were added (4) borrowing food because there was not enough, and (5) stealing food because there was not enough. Each item has a Likert-type response ranging from never $(=0)$, rarely $(=1)$, sometimes $(=2)$ or often $(=3)$. Food insecurity was assessed as a continuous measure of a total scale score (range 0-15). Internal consistency at all time points was acceptable (Cronbach's $\alpha=0.84,0.87,0.86$ at baseline, midline and endline, respectively). In supplemental analysis, food insecurity was defined as a dichotomous outcome (food secure vs food insecure) using validated cutoffs. $^{29}$

Housing was assessed using a single (non-validated) item developed during our formative research that asks about what home a person lives in. The options are ranked by order of more affluent (ie, owning one's home or living in a government-funded house) to more impoverished (ie, living in a shack behind another house, living in a single outside room). Housing was operationalised as a quasi-continuous variable (range 1-6), with a higher score indicating greater housing insecurity. Relationship status was assessed through a single item asking a participant whether he was married and living together, nonmarried but living together, married and living apart, non-married but living apart or single. This was used dichotomously (single vs not) and as a quasi-continuous variable (range 1-5) with higher scores indicating more relational distance. Employment was asked through a single Likert-type item asking how often they worked in the past 12 months: never $(=0)$, rarely $(=1)$, sometimes $(=2)$ or often $(=3)$.

\section{Time-invariant explanatory variables}

We controlled for baseline age in years as a sociodemographic variable as men tend to 'age out' of IPV perpetration as they get older. ${ }^{30}$ Intervention exposure was a dichotomous covariate depending on whether the participant was randomly assigned to an intervention cluster or not. Since this had no measurable effect on food insecurity or IPV exposure it was omitted from the final models.

We controlled for baseline reports of childhood abuse since this predictor strongly influences men's adult use of IPV. ${ }^{16}$ Childhood abuse was measured using 15-item revised Childhood Trauma Questionnaire, a shortened version of an instrument that has been used previously in South Africa. The tool asked participants to self-report frequency of emotional, physical and sexual abuse before the age of 18 ( 4 items, 2 items, and 3 items, respectively), and whether they witnessed their mother being beaten by her husband or boyfriend. A higher score reflected more severe levels of childhood trauma and the internal consistency was good (Cronbach's $\alpha=0.85$ ).

\section{Analysis}

This secondary data analysis was not pre-registered. We first used descriptive statistics to describe the cohort at baseline measurement using svy commands in StataMP V.16 (StataCorps). Bivariate inferential statistics accounting for the clustered nature of the data estimate the cross-sectional association between IPV perpetration and our main variables of interest.

The first models we assessed were cross-sectional and lagged logistic regressions adjusting for clustering by neighbourhood using svy commands. The purpose in estimating these models was to identify the magnitude and direction of the relationship between food insecurity and IPV perpetration, without regard to reciprocal effects. ${ }^{31}$ These also allowed for ease of interpretation since they report ORs.

We then estimated cross-lagged dynamic panel data models (DPMs). Described fully elsewhere, ${ }^{32}$ cross-lagged DPMs are a relatively new analytic technique that unite cross-lagged and fixed effects in the same model using a structural equation modelling (SEM) framework. Fixed effects are useful as they eliminate the effects of all time-invariant confounders even when the potential confounders are unmeasured or undefined. ${ }^{31}$ Fixed effects models estimate within-person changes, ${ }^{33}$ in this case determining how a person's food security level changes over time and how this is related to their IPV perpetration.

We estimated DPMs that incorporated reciprocal, lagged effects of the key variables: food insecurity and 
Table 1 Descriptive statistics at three study timepoints

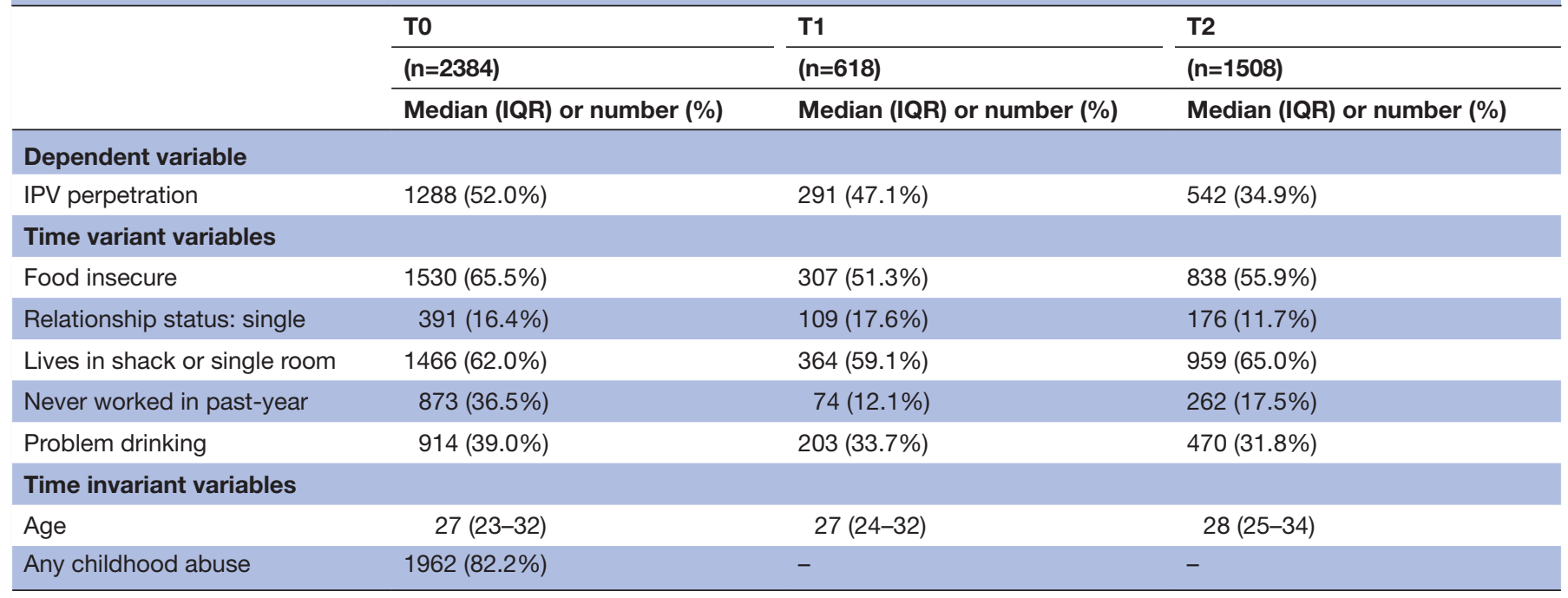

All time variant variables and the dependent variables are presented as at baseline.

IPV, intimate partner violence.

IPV perpetration. ${ }^{31}$ Unlike traditional fixed effects-only models, creating DPMs within the SEM framework allows estimation of two or more variables that may have lagged, reciprocal effects on each other. ${ }^{34}$ This is important since it is plausible that IPV perpetration could lead to future food insecurity. The lagged, reciprocal effects of IPV perpetration on future food insecurity are included in the SEM model by regressing food security in T2 against IPV perpetration and other covariates measured in T0 and $\mathrm{T} 1 .^{32}$

In addition to food insecurity, we extended the unadjusted models described above to include housing status and relationship status. As employment status alcohol use did not demonstrate statistical significance at the $\mathrm{p}<0.20$ value, we removed them from the final model. In conducting DPMs within the SEM framework, one has the option of considering how past violence use influences later violence use. We incorporated this into the model by controlling for IPV perpetration lagged by one timepoint.

All lags were 1 year, as data collection occurred at baseline, 12 months, and 24 months. We use maximum likelihood with missing values to address missing values. Final model estimates are presented after adjusting for clustering by neighbourhood.

\section{RESULTS}

The cohort was composed of 2479 men at T0, of whom $1508(63 \%)$ were followed to T2, 24 months after study enrolment (table 1). Men were a median of 27 years old (range: 18-40 years) at T0.

A total of $1288(52.0 \%)$ men reported perpetrating physical and/or sexual IPV in the past year at T0. This proportion was consistent at $\mathrm{T} 1$, when $47.1 \%$ enacting past-year IPV. At T2 542 men (34.9\%) reported past-year IPV.

Food insecurity was consistently reported over time. At T0, 65.5\% participants reported food insecurity. At $\mathrm{T} 1$ the proportion was similar $(51.3 \%)$ and by $\mathrm{T} 2$ it had increased slightly ( $55.9 \%$, respectively). Men who were food insecure at baseline reported considerably higher rates of IPV at all three timepoints (figure 1).

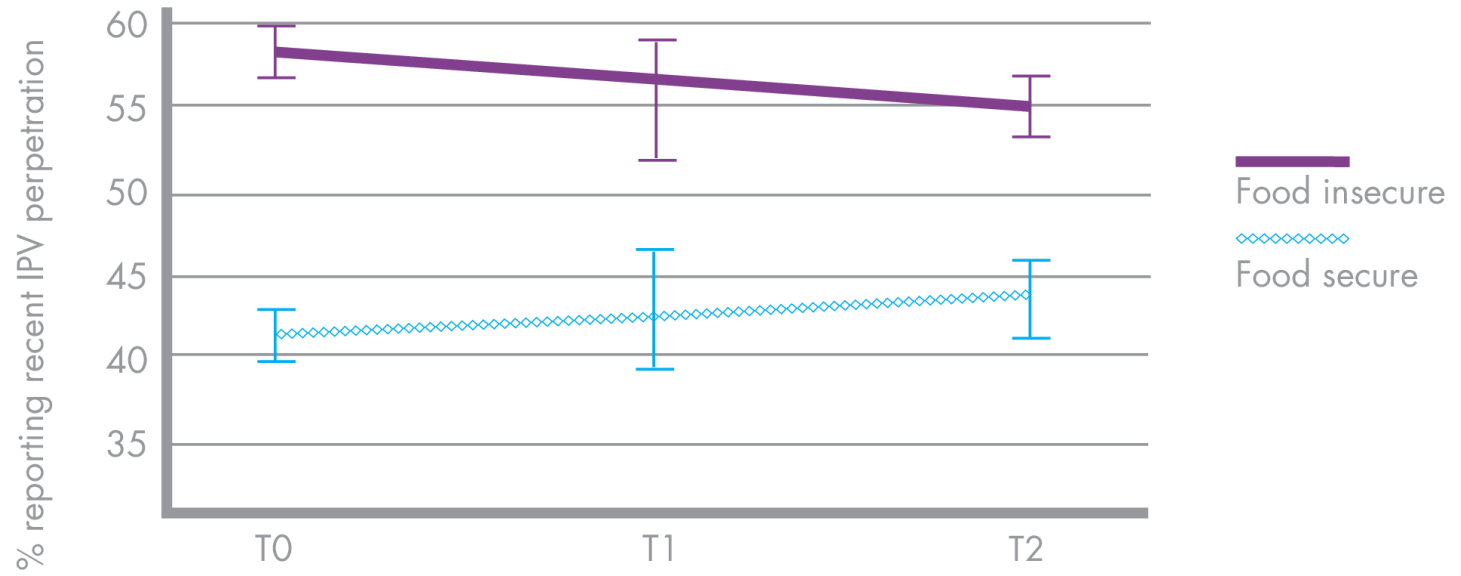

Figure 1 Men's intimate partner violence (IPV) perpetration by food security status. 
Table 2 Association between food insecurity and men's perpetration defined as physical and/or sexual IPV

\begin{tabular}{llll}
\hline & \multicolumn{4}{l}{ Any IPV perpetration } \\
\cline { 2 - 4 } & T0 & T1 & T2 \\
\cline { 2 - 4 } & OR & OR & OR \\
\hline Food insecure T0 & $\mathbf{1 . 8 5 ^ { \star * * }}$ & $\mathbf{1 . 4 0}^{*}$ & $\mathbf{1 . 3 6 ^ { \star * }}$ \\
Food insecure T1 & 1.02 & 1.31 & 1.05 \\
\hline Food insecure T2 & 1.17 & 1.35 & $\mathbf{1 . 3 1 ^ { * * }}$ \\
\hline
\end{tabular}

Logistic regression models account for clustering by neighbourhood.

${ }^{*} \mathrm{p}<0.05,{ }^{* *} \mathrm{p}<0.01,{ }^{* * *} \mathrm{p}<0.001$

IPV, intimate partner violence.

\section{Bivariate analysis}

In clustered bivariate analysis, food insecurity was associated with higher IPV perpetration at multiple timepoints (table 2). Men reporting food insecurity at T0 had higher odds of past-year IPV use at T0 (OR=1.85, 95\% CI 1.61 to 2.12$)$, at $\mathrm{T} 1(\mathrm{OR}=1.40,95 \%$ CI 1.01 to 1.96$)$ and at T2 (OR=1.36, 95\% CI 1.36 to 1.69$)$. Not all associations reached statistical significance but all show a similar direction.

\section{Cross-lagged dynamic panel models}

We present cross-lagged dynamic panel models that lag food insecurity by lyear and model the effects on later IPV perpetration (table 3). In model 1, only food insecurity is considered and changes in food are associated with a small but significant increase in IPV perpetration 1 year later. Every standardised increase in food insecurity is associated with a $0.07(\mathrm{p}=0.045) \mathrm{SD}$ increase in IPV intensity. Model fit indices are good (root mean squared error of approximation $($ RMSEA) $=0.044$, comparative fit index $(\mathrm{CFI})=0.984)$.

In model 2, we added a time-invariant measure (childhood abuse exposure) and time-variant predictors (housing status, relationship status and past IPV perpetration). In this model, food insecurity retains its consistent association with later IPV perpetration ( $\operatorname{coef}=0.09$, $\mathrm{p}=0.034$ ) even after controlling for other covariates and bidirectionality of IPV leading to later food insecurity. Declines in housing status have a similar magnitude of effect on later IPV perpetration (coef $=0.12, p=0.009$ ) as does younger age $(\operatorname{coef}=-0.10, \mathrm{p}<0.001)$. Childhood abuse exposure has a strong effect on IPV perpetration $($ coef $=0.24, p<0.001)$. Fit indices are excellent (RMSEA $=0.016$, CFI=0.994, figure 2).

We examined lagged IPV use as a predictor of later food insecurity, while controlling for housing, age at baseline and childhood abuse (online supplemental table 1). In this model, men's IPV perpetration is not a driver of later food security $(p=0.276)$. On the other hand, age at baseline and childhood abuse do predict adult food insecurity $(p<0.001$ and $p<0.001$, respectively). Model fit was poor (RMSEA $=0.080$, CFI $=0.661$ ), suggesting that a reverse causal hypothesis of IPV perpetration leading to later food insecurity do not fit these data.

\section{DISCUSSION}

In this study, we found that food insecurity had significant association with men's IPV perpetration 1 year later. Of 2479 men from South Africa, roughly half $(52.0 \%)$ reported recent use of IPV and a majority $(65.5 \%)$ were food insecure at baseline. Food security was associated

Table 3 Cross-lagged dynamic panel models examining intensity of IPV perpetration $(n=2479)$

\begin{tabular}{|c|c|c|c|c|c|c|}
\hline & \multicolumn{3}{|c|}{ Model 1} & \multicolumn{3}{|c|}{ Model 2* } \\
\hline & Coef & SE & $P$ value & Coef & SE & $P$ value \\
\hline \multicolumn{7}{|c|}{ Time variant variables } \\
\hline Housing status & - & - & - & 0.12 & 0.05 & 0.009 \\
\hline Relationship status & - & - & - & 0.12 & 0.04 & 0.153 \\
\hline \multicolumn{7}{|c|}{ Time invariant variables } \\
\hline Age at baseline & - & - & - & -0.10 & 0.03 & $<0.001$ \\
\hline Childhood abuse & - & - & - & 0.21 & 0.03 & $<0.001$ \\
\hline Alpha & 0.77 & 0.05 & $<0.001$ & 0.59 & 0.06 & $<0.001$ \\
\hline \multicolumn{7}{|l|}{ Fit indices } \\
\hline $\mathrm{Chi}^{2}$ & 6.56 & & & 7.64 & & \\
\hline CFI & 0.984 & & & 0.994 & & \\
\hline
\end{tabular}

Models account for past use of violence and bidirectional nature of association (ie, IPV perpetration leading to later food insecurity). $\mathrm{CFI}$, comparative fit index; Coef, standardised coefficient; IPV, intimate partner violence; RMSEA, root mean squared error of approximation. 


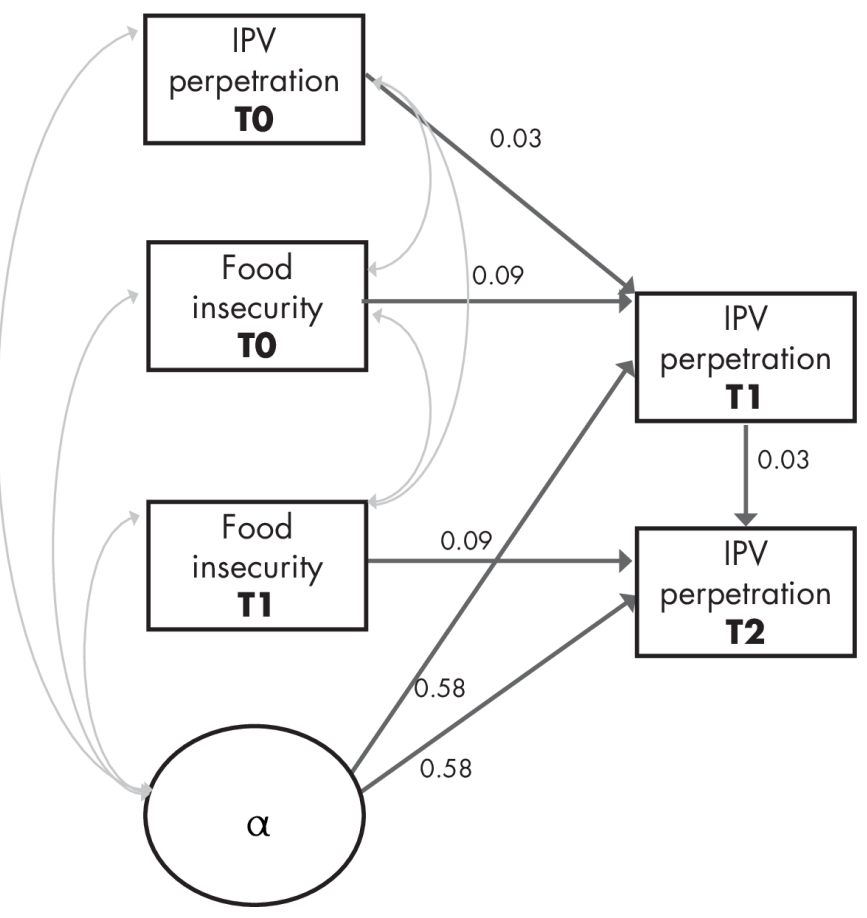

Figure 2 Path diagram for three-wave dynamic panel model of food insecurity to later IPV perpetration (adapted with permission from Allison et $\mathrm{a}^{32}$ ). All $\mathrm{p}<0.05$, estimates are standardised coefficient, root mean squared error of approximation: 0.016 (0.001 to 0.035), comparative fit index: 0.994. Model accounts for clustering by neighbourhood, age, housing, relationship status, childhood exposure to abuse and bidirectionality of IPV towards later hunger. IPV, intimate partner violence.

with higher cross-sectional odds of IPV perpetration. Men's IPV perpetration was predicted by their food security 1 year prior. The measurable longitudinal effect of food security on IPV perpetration was consistent even when controlling for changes in housing and relationship status and baseline age and reports of childhood exposure to abuse.

There is theoretical plausibility to the notion that food insecurity may lead to IPV perpetration. Stress theory suggests that a lack of material resources may lead to violence as stress depletes psychological resources required to enact self-control over the violence act. ${ }^{11} 35$ Stress theory has been supported in empirical studies from both low-income and high-income settings. ${ }^{11}$ 36-38 In a broader 'mental health' lens that extends beyond only stress, we previously found food insecurity was related to greater depression symptoms, which in turn was associated with higher odds of IPV perpetration. ${ }^{17}$

Notwithstanding the longitudinal design of our study, it is plausible that other structural or historical factors drive both food insecurity and men's use of IPV. We attempted to account for this by including fixed effects in the model, which control for within-person, unmeasured covariates. We also assessed results using clustering commands, which helps parse out distinctions between neighbourhoods. However, all of the neighbourhoods were within the peri-urban settlement, which has resource constraints that precludes generalising findings to other types of settings. A future study might examine other structural conditions that have been shown to predict both food insecurity and IPV, such as income inequality or racial discrimination.

Childhood abuse was strongly predictive of adult IPV perpetration. Child abuse is well-recognised as a major longitudinal driver of men's later violence in adulthood. ${ }^{39-41}$ The reasons for this may be causal if those children who live in poorer households, with shifting household composition and childhood food insecurity, are at higher risk of childhood violence. ${ }^{42-44}$ They may also be associated if household conditions that are predictive of childhood abuse are also associated with adult poverty.

\section{Implications for programme and policy}

These data suggest that household food insecurity may be a modifiable risk factor for men's perpetrating IPV. Increasing access to food, through nutrition support, could attenuate men's IPV perpetration, though experimental evidence for this is limited. One Mauritian study suggests that supplementing child nutrition can measurably reduce a father's IPV perpetration, ${ }^{45}$ but it did not parse out the mechanisms through which nutrition might have led to this shift in violence.

Cash transfer programmes with women have shown that offering families a cash grant can reduce women's IPV exposure, ${ }^{46-48}$ yet in a setting like South Africa where a large proportion of the population already depend on cash grants, it is unclear how additional transfers would alter rates of violence. Little research has explored food insecurity or economic interventions among men, but pilot studies suggest these programmes may reduce IPV perpetration. ${ }^{490}$ Despite potential downsides if economic interventions reinforce traditional male roles, concerns that an influx of cash might actually increase violence perpetration (by, eg, increasing alcohol intake) have not been borne out in the literature. ${ }^{51}$

One particularly interesting advance in development economics is the increased focus on assets and savings, rather than loans and credits. Increasing a family's assets (through savings or individual development accounts, for example) seems to have a marked decrease in family stress. ${ }^{52}$ While savings approaches have begun to be tested among female survivors, ${ }^{53}$ our results suggest that they may be valuable for men. If coupled with gender transformative training, such savings and asset building programming could have health outcomes related to IPV perpetration.

\section{Limitations}

Our data are drawn from a convenience sample of men recruited for a cluster randomised controlled trial, precluding the ability to generalise findings to the entire peri-urban settlement or other settings. The anonymity of ACASI may assist with accurate reporting of IPV by men 
by limiting social desirability bias. The data were collected as part of a larger cluster randomised trial, which we control for in analyses. One important assumption in fixed effects models is that the unmeasured confounders (denoted by) are accounted for so long as they stable over time.$^{55}$ For example, study arm (intervention vs control) is stable over time and is thus incorporated in the estimate. However, it is possible that unmeasured timevariant confounders, such as crime experienced in daily life, do change over time.

Dynamic panel modelling is a within-person analysis approach that predicts how changes in one man's food security status may relate to his perpetration of IPV over time. It does not, however, provide information about population-level considerations. Due to high levels of attrition over time there are limitations to the conclusions we can make, though the estimation strategy of maximum likelihood for missing values does partly address this concern. We cannot rule out bidirectionality fully, since it is possible that longer lags would have shown that changes in men's violence use over time does influence their later food security status. However, within these timeframes, we can state the model fit for food insecurity driving later violence is stronger.

\section{CONCLUSION}

We found that food insecurity is longitudinally associated with IPV perpetration among men. These findings can inform future violence prevention efforts, particularly in settings with high rates of endemic poverty. While a bidirectional relationship is plausible, our findings suggest that food insecurity seems to drive later violence rather than vice versa. Urgent policy and programmatic response to the intersecting issues of poverty and IPV can ensure health and well-being.

Acknowledgements We are grateful to participants in this research, the entire trial study team led by Andile Zabeko and Bongwekazi Rapiya, and for community members and Advisory Board who guided the analysis. Ruari Santiago McBride, Shehnaz Munshi, and Nkululeko Ndlovu led exceptional ethnographic and qualitative research informing our analysis. We also remember our colleague Mzwakhe Khumalo whose energy for addressing food concerns alongside violence grounded our work.

Contributors AMH, DR and NJC planned the study. AMH, DR and NJC collected the data. SW guided data collection tools and study conceptualization. AMH and TBN led the analysis. AMH is the guarantor with full responsibility for the work and the conduct of the study, including the decision to publish. All authors critically reflected on the manuscript and approved the final version.

Funding This study is funded through the What Works To Prevent Violence? A Global Programme on Violence Against Women and Girls (VAWG) funded by the UK Government. We also received funding from the South African Medical Research Council Social Innovation Bond, with support from the Global Fund to Fight Malaria, AIDS and Tuberculosis. AMH is supported by NIH MH12118501 and SDW is supported by NIH K24Al134326.

Competing interests None declared.

Patient consent for publication Consent obtained directly from patient(s).

Ethics approval This study involves human participants and was approved by University of the Witwatersrand Human Research Ethics Committee (Medical): M150443. Participants gave informed consent to participate in the study before taking part.
Provenance and peer review Not commissioned; externally peer reviewed.

Data availability statement Data are available in a public, open access repository. Data are available at : https://medat.samrc.ac.za/index.php/catalog/WW.

Open access This is an open access article distributed in accordance with the Creative Commons Attribution 4.0 Unported (CC BY 4.0) license, which permits others to copy, redistribute, remix, transform and build upon this work for any purpose, provided the original work is properly cited, a link to the licence is given, and indication of whether changes were made. See: https://creativecommons.org/ licenses/by/4.0/.

\section{ORCID iDs}

Abigail M Hatcher http://orcid.org/0000-0002-4150-1405

Torsten B Neilands http://orcid.org/0000-0001-7936-9123

Sheri D Weiser http://orcid.org/0000-0002-7807-4072

Nicola J Christofides http://orcid.org/0000-0002-3559-6401

\section{REFERENCES}

1 WHO. Violence against women prevalence estimates, 2018: global, regional and national prevalence estimates for intimate partner violence against women and global and regional prevalence estimates for non-partner sexual violence against women. Geneva: World Health Organization, 2021.

2 Brownridge DA, Halli SS. Double jeopardy?: violence against immigrant women in Canada. Violence Vict 2002;17:455-71.

3 Caetano R, Vaeth PAC, Ramisetty-Mikler S. Intimate partner violence victim and perpetrator characteristics among couples in the United States. J Fam Violence 2008;23:507-18.

4 Pan HS, Neidig PH, O'Leary KD. Predicting mild and severe husband-to-wife physical aggression. J Consult Clin Psychol 1994;62:975-81.

5 Koenig MA, Stephenson R, Ahmed S, et al. Individual and contextual determinants of domestic violence in North India. Am J Public Health 2006;96:132-8.

6 Martin SL, Moracco KE, Garro J, et al. Domestic violence across generations: findings from northern India. Int J Epidemiol 2002;31:560-72.

7 Fleming PJ, McCleary-Sills J, Morton M, et al. Risk factors for men's lifetime perpetration of physical violence against intimate partners: results from the International men and gender equality survey (images) in eight countries. PLoS One 2015;10:e0118639.

8 Jewkes R, Dunkle K, Koss MP, et al. Rape perpetration by young, rural South African men: prevalence, patterns and risk factors. Soc Sci Med 2006;63:2949-61.

9 Costa BM, Kaestle CE, Walker A, et al. Longitudinal predictors of domestic violence perpetration and victimization: a systematic review. Aggress Violent Behav 2015;24:261-72.

10 Krishnan S, Rocca CH, Hubbard AE, et al. Do changes in spousal employment status lead to domestic violence? insights from a prospective study in Bangalore, India. Soc Sci Med 2010;70:136-43.

11 Fox GL, Benson ML, DeMaris AA, et al. Economic distress and intimate violence: testing family stress and resources theories. $J$ Marriage Fam 2002;64:793-807.

12 Coudouel A, Hentschel JS, Wodon QT. Poverty measurement and analysis. In: A Sourcebook for poverty reduction strategies. , 2002: 1, 27-74.

13 Breiding MJ, Basile KC, Klevens J, et al. Economic insecurity and intimate partner and sexual violence victimization. Am J Prev Med 2017;53:457-64.

14 Melchior $\mathrm{H}$, Hergert A, Hofreuter-Gätgens $\mathrm{K}$, et al. [Predictors of treatment duration for inpatients with mental disorders--a systematic literature review]. Z Psychosom Med Psychother 2010;56:399-418.

15 Ricks JL, Cochran SD, Arah OA, et al. Food insecurity and intimate partner violence against women: results from the California women's health survey. Public Health Nutr 2016;19:914-23.

16 Fulu E, Jewkes R, Roselli T, et al. Prevalence of and factors associated with male perpetration of intimate partner violence: findings from the un Multi-country cross-sectional study on men and violence in Asia and the Pacific. Lancet Glob Health 2013;1:e187-207.

17 Authors. 2019.

18 Hatcher AM, van Eck LA, Fielding-Miller R, et al. Association between food insecurity and intimate partner violence: a systematic review of the literature. in preparation.

19 Lindhorst T, Oxford M, Gillmore MR. Longitudinal effects of domestic violence on employment and welfare outcomes. $J$ Interpers Violence 2007;22:812-28.

20 Peterson C, Kearns MC, Mclntosh WL, et al. Lifetime economic burden of intimate partner violence among U.S. adults. Am J Prev Med 2018;55:433-44. 
21 Coker AL. Does physical intimate partner violence affect sexual health? A systematic review. Trauma Violence Abuse 2007;8:149-77.

22 Gibbs A, Duvvury N, Scriver S. What works evidence review: the relationship between poverty and intimate partner violence. Pretoria: South African Medical Research Council, 2017.

23 Mushongera D, Zikhali P, Ngwenya P. A multidimensional poverty index for Gauteng Province, South Africa: evidence from quality of life survey data. Soc Indic Res 2017;130:277-303.

24 Christofides NJ, Hatcher AM, Pino A, et al. A cluster randomised controlled trial to determine the effect of community mobilisation and advocacy on men's use of violence in periurban South Africa: study protocol. BMJ Open 2018;8:e017579.

25 Jewkes R, Sikweyiya $\mathrm{Y}$, Morrell R, et al. The relationship between intimate partner violence, rape and HIV amongst South African men: a cross-sectional study. PLoS One 2011;6:e24256.

26 García-Moreno C, Jansen HA, Ellsberg M, et al. WHO Multicountry Study on Women's Health and Domestic Violence against Women: Initial results on prevalence, health outcomes and women's responses. Geneva: WHO, 2005.

27 Radimer KL, Olson CM, Greene JC, et al. Understanding hunger and developing indicators to assess it in women and children. J Nutr Educ 1992;24:36S-44.

28 Bickel G, Nord M, Price C, et al. Guide to measuring household food security, revised 2000. Alexandria, VA: U.S. Department of Agriculture, Food and Nutrition Service.

29 Deitchler M, Ballard T, Swindale A, et al. Validation of a measure of household hunger for cross-cultural use. Washington, DC: Food and Nurtrition Technical Assistance II Project (FANTA-2), Acedemy for Educational Development, 2010.

30 Moffitt TE. Male antisocial behaviour in adolescence and beyond. Nat Hum Behav 2018;2:177-86.

31 Levanon A, England P, Allison P. Occupational feminization and pay: assessing causal dynamics using 1950-2000 U.S. census data. Social Forces 2009:88:865-91.

32 Allison PD, Williams R, Moral-Benito E. Maximum likelihood for cross-lagged panel models with fixed effects. Socius 2017;3:237802311771057.

33 Boman JH, Mowen TJ. The role of turning points in establishing baseline differences between people in developmental and lifecourse criminology. Criminology 2018;56:191-224.

34 Allison PD. Fixed effects regression models. SAGE publications, 2009.

35 Baumeister RF, Heatherton TF, Tice DM. Losing control: how and why people fail at self-regulation. Academic press, 1994.

36 VanderEnde KE, Sibley LM, Cheong YF, et al. Community economic status and intimate partner violence against women in Bangladesh: compositional or contextual effects? Violence Against Women 2015;21:679-99.

37 Lucero JL, Lim S, Santiago AM. Changes in economic hardship and intimate partner violence: a family stress framework. J Fam Econ Issues 2016;37:395-406.

38 Buller AM, Hidrobo M, Peterman A, et al. The way to a man's heart is through his stomach?: a mixed methods study on causal mechanisms through which cash and in-kind food transfers decreased intimate partner violence. BMC Public Health 2016;16:488.

39 Hébert M, Daspe Marie-Ève, Lapierre A, et al. A meta-analysis of risk and protective factors for dating violence victimization: the role of family and peer interpersonal context. Trauma Violence Abuse 2019;20:574-590.

40 Roberts AL, McLaughlin KA, Conron KJ, et al. Adulthood stressors, history of childhood adversity, and risk of perpetration of intimate partner violence. Am J Prev Med 2011;40:128-38.

41 Jewkes R, Fulu E, Roselli T, et al. Prevalence of and factors associated with non-partner rape perpetration: findings from the un Multi-country cross-sectional study on men and violence in Asia and the Pacific. Lancet Glob Health 2013;1:e208-18.

42 Meinck F, Cluver LD, Boyes ME, et al. Risk and protective factors for physical and emotional abuse victimisation amongst vulnerable children in South Africa. Child Abuse Rev. 2015;24:182-97.

43 Akmatov MK. Child abuse in 28 developing and transitional countries--results from the Multiple Indicator Cluster Surveys. Int J Epidemiol 2011;40:219-27.

44 Richter LM, Dawes ARL. Child abuse in South Africa: rights and wrongs. Child Abuse Review 2008;17:79-93.

45 Portnoy J, Raine A, Liu J, et al. Reductions of intimate partner violence resulting from supplementing children with omega-3 fatty acids: a randomized, double-blind, placebo-controlled, stratified, parallel-group trial. Aggress Behav 2018;4410.1002/ab.21769. [Epub ahead of print: 20 May 2018].

46 Bobonis GJ, González-Brenes M, Castro R. Public transfers and domestic violence: the roles of private information and spousal control. American Economic Journal: Economic Policy 2013:5:179-205.

47 Hidrobo M, Peterman A, Heise L. The effect of cash, vouchers, and food transfers on intimate partner violence: evidence from a randomized experiment in northern Ecuador. Am Econ J Appl Econ 2016;8:284-303

48 Haushofer J, Shapiro J. The short-term impact of unconditional cash transfers to the poor: experimental evidence from Kenya. Q J Econ 2016;131:1973-2042.

49 Jewkes R, Gibbs A, Jama-Shai N, et al. Stepping stones and creating futures intervention: shortened interrupted time series evaluation of a behavioural and structural health promotion and violence prevention intervention for young people in informal settlements in Durban, South Africa. BMC Public Health 2014:14:1325.

50 Heath R, Hidrobo M, Roy S. Cash transfers, polygamy, and intimate partner violence: experimental evidence from Mali. Washington, DC: International Food Policy Research Institute (IFPRI), 2018.

51 Handa S, Daidone S, Peterman A, et al. Myth-busting? confronting six common perceptions about unconditional cash transfers as a poverty reduction strategy in Africa, 2017.

52 Rothwell DW, Han C-K. Exploring the relationship between assets and family stress among low-income families. Fam Relat 2010;59:396-407.

53 Sanders CK. Savings for survivors: an individual development account program for survivors of intimate-partner violence. J Soc Serv Res 2014:40:297-312.

54 Hahn SA, Postmus JL. Economic empowerment of impoverished IPV survivors: a review of best practice literature and implications for policy. Trauma Violence Abuse 2014;15:79-93.

55 Firebaugh G, Warner C, Massoglia M. Fixed effects, random effects, and hybrid models for causal analysis.. In: Handbook of causal analysis for social research. Springer, 2013: 113-32. 